\title{
Educação, Saúde e Cidadania: Investigação Científica e Assessoria Popular ${ }^{1}$
}

\section{Education, Health and Citizenship: Scientific Investigation and Popular Consultancy}

\author{
Victor V. Valla ${ }^{2}$
}

\section{VALLA, V. V. Education, Health and Citizenship: Scientific Investigation and Popular} Consultancy. Cad. Saúde Públ., Rio de Janeiro, 8 (1): 30-40, jan/mar, 1992.

The author relates education and health with citizenship through the discussion of basic services and the taxes the population pays. The contradictions resulting from the unequal distribution of the public money, favoring industrial infrastructure over collective consumption, point towards the need for organized popular sectors of the civil society to pressure governments for alternative policies. The author proposes that professionals from public universities offer, in the spirit of public service, the results of their research as technical support for the demands of these organized sectors. Research results relative to the municipal health center's policy towards the public together with other results relative to environment and health risks to Rio de Janeiro favela residents are exemplified. The text includes a discussion about mutual training of organized popular sectors and professionals from the public service network and/or public universities. The Nesc/DCS/Ensp/Fiocruz experience of Education and Health Workshops is presented, calling attention to the debate between popular leaders and education and health professionals about the inherent contradictions between efficiency and efficacy of the public services. A proposal is made to undertake a participative diagnosis as a way for professionals'popular entities to deal with the precarious quality and quantity of information about health risks to the population.

Keywords: Health and Education; Citizenship; Popular Participation; Public Money; Popular Consultancy

\section{INTRODUÇÃO}

A proposta deste texto é a de discutir a possibilidade de relacionar atividades como as

\footnotetext{
${ }^{1}$ Conteúdo do trabalho apresentado, baseado nos resultados da investigação "Educação, Saúde e Cidadania: Diagnóstico de Experiências Locais de Participação Popular no Sistema de Saúde - Estado do Rio de Janeiro, financiado pela Finep, Inamps, CNPq e Fundação Kellogg. Trabalho apresentado nos encontros nacionais da Associação Nacional de Pesquisa e Pós-Graduaçāo em Psicologia (Anppe) e Associação Nacional de Pós-Graduação em Educação (Anped), Aguas de São Pedro/SP e Belo Horizonte/MG, respectivamente, 1990.

'Departamento de Ciências Sociais e Núcleo de Doenças Endêmicas Samuel Pessoa da Escola Nacional de Saude Pública. Rua Leopoldo Bulhões, 1480, 21041, Rio de Janeiro, RJ, Brasil.
}

de investigação cientifica com as necessidades das organizações populares da sociedade civil. Quando se fala das "necessidades" desses setores organizados, aponta-se também para um debate sobre as carências do movimento popular no Brasil, principalmente sua dificuldade de acesso às informações técnicas necessárias para subsidiar suas reivindicaçōes relativas aos serviços básicos. Neste sentido, há um esforço deliberado, neste trabalho, de evitar um debate sobre "transformação da sociedade brasileira" ou "libertação das classes populares" para situar o debate no território da disputa das forças organizadas pelo acesso à verba pública (Valla, 1988).

O pressuposto da discussão apresentada a seguir é que a configuração essencialmente urbana do país estaria exigindo dessas organi- 
zações a aquisição de subsídios técnicos para poder avançar suas lutas pela conquista de um patamar mais elevado de condições de reprodução da sua força de trabalho e do exercício da cidadania.

O texto a seguir desenvolve reflexões sobre assessoria popular, a partir da experiência do Núcleo de Educação, Saúde e Cidadania (Ensp/Fiocruz), que, desde 1986, vem investigando educação, saúde e cidadania, através de uma relação permanente com profissionais de educação e saúde e usuários organizados, no Grande Rio de Janeiro.

\section{EDUCAÇÃO, SAÚDE E CIDADANIA: DESTACANDO AS RELAÇÕES}

Tradicionalmente, no Brasil, vem se desenvolvendo uma abordagem de educação e saúde que privilegia conselhos e normas para o individuo, fazendo com que o acesso à saúde seja um esforço individual e, conseqüentemente, uma responsabilidade individual. Em contraposição a esse processo de "culpabilizar a vítima por sua doença", é desenvolvida uma proposta de relacionar o processo saúde-doença da população com as suas condições de vida e trabalho.

Quando se relaciona o processo de saúde-doença com as condições de vida e trabalho da classe trabalhadora, é necessário apontar para as políticas sociais desenvolvidas pelos governos brasileiros nos últimos anos, pois uma grande parcela dos condicionantes de saúde da população se refere ao acesso e à qualidade dos serviços básicos (Brown \& Margo, 1978; Ryan, 1979; Stotz, 1989; Valla, 1987). É oportuno ressaltar que os gastos do governo brasilciro com programas sociais são elevados, mas beneficiam os grupos economicamente mais favorecidos, e não os de baixa renda. De acordo com as conclusões dos relatórios do Banco Mundial, gasta-se mais com o ensino superior, com a medicina curativa e com financiamentos habitacionais para as classes médias e alta do que com o ensino de $1^{9}$ grau, medicina preventiva e programas habitacionais populares (Jornal do Brasil, jul. 1988).

Quando se fala dos serviços básicos para a população, está se referindo ao que se chama "consumo coletivo", isto é, consumo que a população em geral, e, em particular, a população trabalhadora, precisa para renovar suas forças. Esses serviços são da direta responsabilidade dos governos, e é a população que, com seus impostos, paga os recursos necessários para manter esses serviços (Valla \& Siqueira, 1989).

O processo de industrialização requer também pesados investimentos, que são freqüentemente feitos com o dinheiro que o governo coleta para atender ao consumo coletivo. Assim como há uma infra-estrutura da qual a população necessita para se refazer de um dia para o outro, há também uma infra-estrutura necessária para as indústrias poderem funcionar. Esta se chama infra-estrutura industrial e abrange os investimentos que o próprio governo faz na construção de indústrias, abastecimento de água, eletricidade, freqüentemente para abrir estradas, construir usinas, barragens, viadutos e pontes. E todos esses serviços são também da responsabilidade dos governos, e obviamente envolvem muitos recursos.

A verba pública freqüentemente utilizada para fins industriais é exatamente aquela verba que deveria fornecer os serviços básicos para a população. Mas, uma vez que o governo privilegia os gastos com a infra-estrutura industrial, é a própria classe trabalhadora que acaba assumindo grande parte dos custos da reprodução da sua força de trabalho (Valla \& Stotz, 1989).

$\mathrm{Na}$ realidade, nem todos têm acesso igual ao dinheiro público, embora todos sejam obrigados a contribuir com seus impostos. A proposta de participação popular se coloca justamente na contramão desse estado de coisas.

Nos regimes democráticos, há a proposta que os direitos "individuais" de cada cidadão sejam respeitados. Mas essa proposta somente teria sentido se todos os cidadãos brasileiros tivessem acesso pleno aos serviços básicos. Como garantir o "direito de ir e vir", por exemplo, se o transporte coletivo ou não existe (obrigando a longas caminhadas) ou é extremamente precário, com horário irregular, poucos ônibus, etc.? O dinheiro que os governos gastam com o consumo coletivo está longe de ser suficiente para proprorcionar a toda a população tudo o que a Constituição prevê, dessa forma prejudi- 
cando o exercício pleno dos direitos individuais.

$\mathrm{Na}$ realidade, tentar responder a essas questões é falar de cidadania. Mas a discussão da cidadania no Brasil é problemática, porque a idéia que tem sido divulgada é a de uma cidadania do Primeiro Mundo, onde os cidadãos mais conscientes dos Estados Unidos e dos países da Europa Ocidental vigiam seus governos para garantir que os serviços já existentes e abundantes continuem dessa forma. Trata-se de uma "cidadania de abundância, de vigilância".

No Brasil, porém, uma grande parte da população não pode vigiar o governo, porque não há o que vigiar; a populaçāo sem acesso aos serviços básicos tem que pressionar as autoridades para realizarem essas obras com o dinheiro dos impostos.

O que a população reivindica quando exige os serviços básicos é sua sobrevivência, pois não havendo esses serviços muitas pessoas correm o risco de morrer.

Essa é uma "cidadania de sobrevivência", então; uma "cidadania de escassez" que pode ser assim colocada: ou o governo respeita os direitos da população e devolve seu dinheiro na forma de serviços, ou grandes parcelas da população continuam a ter problemas muito sérios de saúde (Valla \& Siqueira, 1989).

É possível afirmar, então, que uma forma de caracterizar a cidadania na América Latina seria relacioná-la com o conceito de reprodução da força de trabalho. Neste sentido, poder-se-ia dizer que o grau de cidadania de uma população varia de acordo com sua capacidade de garantir maior ou menor qualidade na reprodução da sua força de trabalho.

Nesta perspectiva, é possível entender a participação popular, ou a participação efetiva da população organizada. A participação é "efetiva" quando pretende ou consegue modificar o orçamento estatal, de modo a oferecer os serviços básicos para a população (Valla \& Stotz, 1989).

O uso preciso do termo "participaçāo popular" é essencial, pois atores representantes de todas as forças da sociedade utilizam o termo, fazendo com que o seu emprego ambíguo escamoteie a relação "impostos-serviços bási- cos-qualidade de vida" da população trabalhadora (Valla \& Stotz, 1989).

Os governantes pouco sensíveis às idéias progressistas fazem uso freqüente do termo "participação popular", principalmente quando perdem o controle de agravos que ameaçam a população como um todo: epidemias de dengue, meningite, enchentes, acidentes de trânsito, etc. Nestes momentos, fazem campanhas que ensinam a população a identificar os sinais de males que podem ameaçar "toda" a população, e não apenas a classe trabalhadora. Neste sentido, um dos pontos essenciais de uma participação efetiva da população é sua capacidade de apontar as áreas em que julga necessária sua intervenção (Carvalho, 1990; Gomes, 1990).

\section{SUBSIDIANDO OS SETORES POPULARES DA SOCIEDADE CIVIL COM A INVESTIGAÇÃO CIENTÍFICA}

Não se pretende apresentar, nesta parte do texto, uma síntese da investigação científica realizada pela equipe. Apenas selecionamos alguns dos resultados, demostrando nossa compreensão da articulação entre a investigação e a assessoria popular.

O que parece pertinente explicitar é a intenção da equipe de realizar a investigação, seja a partir de documentação, seja através de uma presença sistemática dos pesquisadores nos encontros populares e de serviços de educação e saúde, com o objetivo de devolver à população interessada os dados sistematizados na forma de subsídios.

A equipe de pesquisa desenvolveu a investigação na $\mathrm{XI}^{\mathrm{a}}$ Região Administrativa (Penha), no município do Rio de Janeiro. A XI ${ }^{2}$ Região Administrativa pertence à Área Programática 3.1, que também inclui a $\mathrm{X}^{\mathrm{a}}$ e a $\mathrm{XX}^{\mathrm{a}}$ Regiōes Administrativas (Ramos, Bonsucesso e Ilha do Governador, respectivamente). Foram escolhidos como objeto de investigação a indústria multinacional de couro (Curtume Carioca), o Centro Municipal de Saúde, quatro escolas públicas e algumas associações de moradores de bairros e favelas. Numa segunda etapa da pesquisa, foi incluído o município de Duque de Caxias, na Baixada Fluminense, objetivando o 
Conselho Comunitário de Saúde dentro de uma perspectiva de participação popular.

Foi proposto pela equipe analisar, de um lado, as formas através das quais a sociedade civil demanda (reivindica, compreende, propōe) serviços de saúde. Mais especificamente, como determinada parcela da população - as chamadas "classes trabalhadoras organizadas" - luta pelo acesso aos serviços de saúde de qualidade. Por outro lado, pretende-se analisar a resposta de algumas instituiçōes públicas a essa demanda: a Escola Pública, Centro Municipal de Saúde, Fundação Estadual de Ecologia e Meio Ambiente (Feema), Companhia Estadual de Água e Esgoto (Cedae), Companhia Municipal de Limpeza Urbana (Comlurb). Em outros termos, foi proposto analisar como a sociedade se articula e constitui uma rede de relações no campo da luta pelos direitos de cidadania. Estes direitos circunscrevem um campo de luta e de análise: o político-ideológico (Valla et al., 1988).

Há uma questão de fundo que perpassa toda a investigação: a extrema precariedade das condiçōes de vida e de trabalho da população trabalhadora das áreas pesquisadas. É como se a população trabalhadora estivesse diante de uma ameaça permanente à sua própria sobrevivência (Valla et al., 1988).

As políticas sociais do Estado promovem uma fragmentação do proletariado em setores e camadas, de acordo com a sua inserção no mercado de trabalho. A atenção à saúde diferencia-se para dar conta dessa fragmentação: na rede básica, recebe-se os mais "miseráveis", enquanto que a parcela de trabalhadores com vínculos empregatícios e salários um pouco mais altos têm suas necessidades de saúde cobertas por serviços médicos privados, conveniados ou não.

Quanto à definição do quadro das necessidades de saúde da população "carente" ou "favelada", verificamos que é habitualmente o das doenças da miséria, cuja profilaxia, de baixo custo, realiza-se, no caso dos centros de saúde, por meio de medidas como a vacinação em massa. As campanhas e os programas desenvolvidos têm mais a ver com os "agentes patológi$\cos ^{\prime \prime}$ do que com os indivíduos sociais. O conhecimento que embasa os serviços pretende ter uma validade universal: por ser biologista, pressupõe um único padrão de resposta humana à ação daqueles "agentes patológicos".

À medida que se define quem é a população usuária dos serviços de saúde, bem como as suas caracteristicas, abre-se uma perspectiva do próprio movimento popular se organizar para reivindicar uma melhor atenção. Mas essa definição do usuário não é apenas uma questão de mais recursos humanos ou mais turnos. Atualmente, a maioria dos centros de saúde atende a população que se apresenta diariamente de uma forma espontânea ou "passiva".

$O$ atendimento à "demanda passiva" não garante a cobertura da maior parte dos usuários da $X^{a}$ Região Administrativa. Setores das classes populares, atingidos por males como desnutrição ou hanseníase, podem nunca aparecer num centro de saúde justamente por causa das próprias condiçōes de vida, tais como distâncias a percorrer ou vergonha.

Entender o processo saúde/doença como resultante das condições de vida e trabalho significa buscar formas de perceber como ela se revela na coletividade. Nesse esforço, assinala Berliguer (1987), devem estar envolvidos não só os profissionais de saúde, mas também os cidadãos e as instituições públicas.

Nesse sentido, um dos instrumentos básicos que pode ajudar a epidemiologia nessa caracterização é o registro das doenças de notificação compulsória listadas pela Organização Mundial da Saúde. Mesmo reconhecendo a necessidade de não se restringir a elas, a não-notificação pelos profissionais denota a dificuldade dos serviços em construir um perfil epidemiológico da população da área de abragência, bem como na avaliação dos serviços prestados.

Possas (1987) nos auxilia a compreender o impasse que se apresenta com relação aos serviços de saúde e aos problemas de saúde da população. A consolidação da economia brasileira no interior do sistema de capitalismo internacional e a intensificação do processo de industrialização $\mathrm{c}$ urbanização têm resultado num sistema de saúde complexificado, marcado pela combinação de padrōes de morbidade e mortalidade distintos, fazendo com que, muitas vezes, um mesmo individuo apresente patologias variadas, caracteristicas do desenvol- 
vimento e do subdesenvolvimento, o que passa cada vez mais a exigir dos precários serviços locais de saúde uma maior diversificação $e$ complexidade do atendimento oferecido, além do aumento de seu volume (op. cit., pag. 241).

Mas a resposta a essa complexificação tem sido uma progressiva simplificação dos procedimentos. Essa tendência à "racionalização e redução dos custos" decorre da crise do sistema previdenciário. $\mathrm{Na}$ realidade, a simplificação, que é expressão da "medicina comunitária", é resultado de um modelo econômico já existente no Brasil por mais de 40 anos, mas cuja consolidação e intensificação ocorrem a partir do golpe militar de 1964. Praticar esse tipo de medicina tem significado validar o modelo de distribuição das verbas públicas pelo governo, que, como já foi dito, privilegia os investimentos na produção e reprodução do capital (Valla et al., 1988).

Viver em permanente estado de emergência, de ameaça à vida, constitui o quadro real de grande parcela da população trabalhadora no Brasil. Há situações em que essa ameaça é dramatizada num nível global, deixando evidente para toda população a incapacidade do Estado, em seus diferentes níveis de serviços, de dar soluções satisfatórias.

Em áreas metropolitanas como a do Rio de Janeiro, onde vivem mais de doze milhões de pessoas, os problemas sanitários adquirem uma gravidade dramática, em virtude de acidentes naturais ou tecnológicos de dimensão coletiva.

Tais acidentes são normalmente precedidos por uma série de "pequenas catástrofes", ou ocorrem concomitantemente às mesmas, as quais localizam-se em ruas ou áreas restritas de bairros, a exemplo da contaminação da rede de água. Ou por uma contínua e quase imperceptível degradação do modelo de ambiente urbano: diariamente, inúmeros poluentes atmosféricos emanados de diferentes fontes (veículos, indústrias, queima de lixo) atuam concomitantemente. Da mesma forma, a devastação das encostas nos morros, para fins de habitação, e o despejo habitual do lixo seguem um curso "normal". Apenas para termos uma idéia desse processo, a imprensa notificou que, entre 1976 e 1988 , as áreas desmatadas aumentaram 10,36\%. Desde o início da colonização, em quatro séculos, o
Rio de Janeiro teve $40 \%$ de suas florestas destruídas. É importante assinalar que não é apenas a ocupação para fins residenciais que conduz ao desmatamento das encostas. $\mathrm{Na}$ mesma notícia, fica-se sabendo que a justiça tem mais de 100 ações contra pedreiras e imobiliárias nos morros (Jornal do Brasil, jul. 1988).

Cabe, inicialmente, distinguir os processos que podem originar "calamidades públicas", tipificadas como acidentes naturais, daqueles que resultam em acidentes ambientais e estão relacionados a processos produtivos e tecnológicos. Se é evidente que ambos convergem no sentido de representar uma ameaça coletiva à vida è à saúde da população, a responsabilidade é atribuída a diferentes classes, grupos ou instituições.

No caso de acidentes ditos naturais, como a catástrofe provocada pelas fortes chuvas que dominaram o Rio de Janeiro em fevereiro de 1988, podemos afirmar, sem sombra de dúvida, que houve uma distribuição desigual da tragédia: enquanto os moradores das favelas localizadas em torno do Maciço da Tijuca perdiam barracos, adoeciam e morriam, os moradores de classe média no bairro da Tijuca ou Gávea tinham seus automóveis destruídos.

No periodo de 18 a 24 de fevereiro de 1988 , 84 pessoas ficaram feridas, 16.084 ficaram desabrigadas e 82 morreram em conseqüência de desabamentos de barracos. Para o estado do Rio de Janeiro, abrangendo as cidades da Região Metropolitana, os dados sobre a epidemia de leptospirose, ainda não definitivos, indicam, desde aquela data até 8 de março, um total de 772 casos e 44 óbitos.

Epidemias como a leptospirose estão relacionadas ao aumento dos locais de proliferação de vetores (como o aterro sanitário de lixo que existe em Duque de Caxias, onde a proporção é de 4 ratos para cada habitante), à situação sanitária precária nas moradias e à quebra de programas de rotina. Por outro lado, os problemas de saúde relacionados às calamidades incluem maior significado das doenças crônico-degenerativas na morbi-mortalidade relacionada a estas situações (Lichat, s.d.).

Do ponto de vista da ideologia dominante, veiculada pela imprensa e meios de comunicação de massa, os favelados são considerados 
os responsáveis imediatos pela situação. A culpabilidade da vítima assume, no pronunciamento da Deputada Sandra Cavalcante, a caracterização de crime ecológico, uma vez que a populaçẫo favelada explora predatoriamente a topografia da cidade, crime de co-responsabilidade das autoridades desde que os administradores limitam-se a pastorear as favelas, seus currais eleitorais (Jornal do Brasil, fev. 1988).

A tentativa do "romper" com o círculo vicioso passa por dois tipos de reinvidicações: as do tratamento e da prevenção da doença em si, mesmo através da rede hospitalar e dos centros de saúde; e as do tratamento de infra-estrutura necessária para a reprodução da força de trabalho, isto é, água, luz, saneamento básico, transporte público, etc.

Certamente, as demandas do segundo tipo, relacionadas às causas básicas de doenças infecto-contagiosas, são encaminhadas ao Estado. Porém, são interpretadas de acordo com o seu potencial de resolutividade a nivel civil, ou seja, a população tenta "resolver" suas questōes autonomamente, de diversas formas. Sendo portadora de uma história e de cultura comunitárias - que começa com a ocupação e posse da terra e desenvolve-se na construção dos barracos -, busca resolver necessidades básicas para reproduzir a sua vida através de grandes mobilizações. As ligações clandestinas de água, luz ou esgoto, realizadas coletivamente, contam sempre com a capacidade de um bombeiro, eletricista ou pedreiro morador da favela, que age como um orientador de "mutirões".

Ao assumir essa "responsabilidade civil", a população que mora em favelas tenta gerenciar ou controlar seus problemas, que decidem o "destino" de sua sobrevivência, porque há a percepção, confirmada pelos fatos repetidos anos a fio, de que o Estado protela continuamente a realização de obras prometidas por políticos e outros "agentes externos". Simultaneamente, em conjunturas mais favoráveis, essa iniciativa popular obriga o Estado a intervir e/ou agilizar suas açōes. Um dos exemplos citados é o das ligaçōes clandestinas de energia elétrica, através dos "gatos". As "novas ligações" ocasionavam curtos e incêncidos e provocavam quedas na voltagem das redes elétricas nos bairros "parasitados". A oficialização do abastecimento veio solucionar este problema nas favelas.

Entendemos que quando falamos da democratização do acesso aos serviços básicos, estamos pressupondo desigualdade entre os participantes; é por essa razão que se propõe a democracia. Nesse sentido, parece importante destacar uma série de constatações que brotam dos resultados, constataçōes estas que apontam para uma imagem que é construída em torno das condições de vida e de trabalho da população trabalhadora. De certa forma, poderíamos dizer que a precariedade dos serviços públicos para essas parcelas da sociedade tem, em parte, sua justificativa a partir dessa imagem construida.

Uma dessas construções é o que chamamos a "culpabilização das vítimas", onde a individualização da culpa acaba explicando uma prática coletiva. Trata-se de acusar os pais de não motivar seus filhos nos estudos para explicar um índice de fracasso escolar que freqüentemente supera $50 \%$ dos alunos das primeiras séries do $1^{\mathscr{Q}}$ grau. Mas trata-se também de acusar o operário acidentado de não prestar atenção ou o pai do filho desidratado de não ofetecer os cuidados necessários à criança.

Frequientemente, a culpabilização ganha contornos mais sofisticados quando, por exemplo, se supervaloriza os problemas sócio-econômicos da população, justificando, assim, os serviços precários. Se, de um lado, há o recurso de explicar o mal funcionamento dos serviços por esse prisma, de outro, cabe perguntar, então, para que servem esses serviços. Exemplos dessa forma de raciocínio incluem explicar a repetência na escola pela falta de condições de estudo do aluno morador na favela, ou da não resolutividade dos casos de verminoses do morador que mora ao lado da vala aberta. Enfim, a inoperância, ausência ou irresponsabilidade social das instituições sociais (que resultam em acidentes de trabalho, doenças infecto-contagiosas e fracasso escolar, entre outras ocorrências) acabam sendo justificadas pelo local de moradia, o baixo salário no emprego, o nível de escolaridade (Stotz \& Neto, 1989).

Uma das justificativas para a culpabilidade 
das vítimas é a da desqualificação do saber popular. Assim, o monopólio do saber técnico, seja médico ou de outro tipo, secundariza o saber acumulado da população trabalhadora quando lança mão da escolaridade formal como parâmetro da competência. Mas a "desqualificação" da classe trabalhadora também passa pela construção de uma imagem do "bruto", do "carente", do "nulo", afirmando, enfim, que a familia pobre é igual a doença. Essa imagem visual do trabalhador, de um lado, tem o resultado de apagar as diversidades no interior da própria classe; de outro lado, procura infantilizar os mesmos trabalhadores, chamando-os de mentirosos, quando alegam problemas de saúde, e "bagunceiros," quando demostram desinteresse na sala de aula (Stotz \& Neto, 1989; Valla et al., 1988; Valla \& Hollanda, 1989; Valla \& Stoz, 1989).

\section{ASSESSORIA POPULAR E A CAPACITAÇÃO TÉCNICA}

A necessidade de ter uma presença constante junto aos serviços de educação e saúde, como também às organizações populares, fez com que a equipe de investigação estivesse presente em mais de 200 encontros/reuniões, durante um período de dois anos. Em virtude deste acompanhamento, a equipe começou a receber convites dos dois setores (profissionais e organizações populares) para expor os primeiros resultados da investigação ou discutir alguns dos eixos do estudo (participação popular, fracasso escolar, por exemplo). Em seguida, vieram convites para prestar uma assessoria à saúde (centro municipal de saúde, hospital público, etc.). O que mais surpreendeu a equipe foi o grande número de pedidos vindos de profissionais de educação e saúde. Supunha-se que as organizações populares fariam pedidos, mas a equipe não esperava tantas solicitações de profissionais.

A necessidade de atender ao grande número de pedidos de assessoria, recebidos não só das áreas investigadas, mas também de outros lugares do município do Rio de Janeiro ou de outros municípios do Estado (Petrópolis, Niterói, São Gonçalo, Volta Redonda e Duque de Caxias), fez com que a equipe propusesse a
Oficina de Estudos de Educação e Saúde, reunindo, por um dia inteiro, a cada dois meses, profissionais de educação e saúde com representantes de organizações populares. Mas se a preocupação inicial era o atendimento do grande número de pedidos, à medida que as oficinas se realizavam, foi possível perceber que havia mais em questão do que apenas assessoria.

Se, de um lado, os representantes de organizações populares vinham buscando informações que não possuíam, os profissionais, por sua vez, demostravam uma preocupação semelhante. $\mathrm{Na}$ realidade, suas formações universitárias revelam lacunas justamente nas áreas de conhecimento que se relacionam com os problemas agudos da população trabalhadora (problemas de aprendizagem de crianças populares, vigilâncias epidemiológica e sanitária, saneamento básico, por exemplo). Neste sentido, a ótica elitista dos curriculos universitários faz com que assuntos tratados nas universidades freqüentemente passem ao longo de questões de educação e saúde ligadas às necessidades da população (Valla, 1989).

O que estava se gestando neste processo de investigação científica, "do ponto de vista popular", era a percepção intuitiva dos pesquisadores, profissionais e população de que a reivindicação dos serviços de educação e saúde poderia ter até o lastro de uma discussāo política, mas careceria freqüentemente de informações técnicas (Corragio, 1989). $\mathrm{Na}$ realidade, o que estava nascendo era um processo de capacitação técnica, envolvendo pesquisadores, profissionais e organizações populares.

Estava em discussão a possibilidade de uma aliança entre os profissionais, que se viam como empregados do Estado, mas, ao mesmo tempo, membros da sociedade civil, e usuários organizados. Nesse sentido, a aliança passaria, prioritariamente, pela reivindicação do uso eficiente e eficaz do dinheiro público, não somente para a gestão de serviços de qualidade, mas também com relação às ameaças coletivas referentes à infra-estrutura sanitária e meio ambiente. A preocupação com a notificação obrigatória de meningite ou dengue $e$ as ameaças à saúde pela poluição do meio ambiente ou as enchentes não seriam vistas apenas como 
problemas dos "outros". Todos os participantes da Oficina seriam "usuários", na medida em que o "cinturão sanitário" diminuísse seu raio de alcance.

Outra percepção possível, a partir da própria realização das oficinas, era que o processo de capacitação técnica dos profissionais e dos usuários podia envolver os dois atores simultaneamente. Dessa forma, afastar-se-ia da postura de que os profissionais podiam ser capacitados em primeiro lugar, devido à sua escolaridade, e posteriormente os usuários. O próprio processo que levou os dois grupos a procurarem a assessoria tornou possível pensar essa capacitação no mesmo espaço de tempo, fazendo com que cada participante entrasse com seus conhecimentos e experiências.

É claro que a equipe de investigação não possui recursos materiais para contemplar um processo de capacitação técnica de uma forma quantitativa, mas encara a oportunidade como uma forma de refletir, juntamente com os participantes, sobre esta relação entre profissional e usuário.

\section{A INVESTIGAÇÃO CIENTÍFICA E A ASSESSORIA POPULAR}

Os resultados da investigação apresentados acima apontam para duas questōes, entre outras, que podem servir como subsídios para a assessoria popular e a capacitação técnica.

A primeira trata de uma questão de fundo, que não somente se refere à investigação em si, mas à própria compreensão de educação e saúde com relação aos serviços. Trata-se da "culpabilização da vítima" quando se refere à eficácia dos serviços. Nesse sentido, "culpados" são os operários por seus acidentes de trabalho, encobrindo, dessa forma, seus direitos ao tempo e aos recursos ncessários para o tratamento; "culpados" são os filhos pela "incapacidade" de "aprender" na sala de aula, encobrindo, dessa forma, os gastos necessários para uma escola de tempo integral e formação mais apurada dos professores; e "culpados" são as mães cujos filhos têm diarréia, os moradores da favela que constroem os barracos na encosta sem vegetação, os pedestres atropelados porque não andavam "com cuidado", etc. (Ryan, 1979; Siqueira \& Brandão, 1990; Stotz, 1989; Valla et al., 1988; Valla \& Hollanda, 1989; Valla \& Siqueira, 1989).

Se, à primeira vista, o processo da "culpabilização da vítima" pode representar um desabafo de funcionários públicos, desesperados com uma demanda muito maior do que a oferta de serviços, a discussão de educação e saúde remete aos gastos públicos necessários, mas não realizados, para mais e melhores recursos humanos e materiais.

Outra constatação foi a da carência de informações dos governos requeridos para poderem fazer um planejamento racional dos serviços pelos agravos da população. Entre encontros formais e conversas informais, foi possível para a equipe perceber que o sistema de levantamento e utilização de dados sobre os agravos à saúde da população é dos mais precários, mesmo numa área do município do Rio de Janeiro extremamente bem servida em termos quantitativos. Numa das primeiras reuniões da Comissão de Vigilância Epidemiológica da A.P. 3.1., foi constatado que apenas cinco das dezesseis unidades dessa A.P. faziam algumas notificações obrigatórias, e mesmo estas cinco unidades a realizam de forma precária (Valla et al., 1988).

Estas constatações apontam para duas questões. A primeira é que estamos lidando com o que se chama de "necessidades não-sentidas" da população. Assim, podemos dizer que não é somente a população trabalhadora que indica suas próprias necessidades e que a investigação científica pode ser um instrumento de apoio às suas lutas.

A segunda questão é que, mesmo reconhecendo que os dados existentes referentes à vigilância epidemiológica se limitam aos parâmetros dos serviços, é possivel constatar sua precariedade. Uma professora da Ensp relatou para a equipe que a diarréia é sempre subnotificada, porque se os funcionários registrassem todos os casos, não teriam tempo para suas outras tarefas, tantas são as crianças acometidas pelo agravo. Doenças como dengue e hepatite são sub-registradas, porque a população já sabe se tratar $\mathrm{e}$, conseqüentemente, não notifica às unidades, dessa forma deixando transparecer 
sua pouca confiança nos serviços. Recentemente, foi revelado informalmente, numa unidade de saúde da Zona Norte do Rio de Janeiro, que profissionais preocupados com a questão da meningite já tinham constatado a existência de uma epidemia da doença há três anos, mas não conseguiram convencer a secretaria municipal, devido a discordâncias metodológicas. Os mesmos profissionais tinham descoberto também $o$ fato de que ocorreram epidemias da doença em anos anteriores, sem qualquer registro das autoridades. A questão ganha em importância quando se percebe que o registro de meningite é dos mais precisos e ágeis no Brasil, atualmente (Carvalho, 1990).

Num encontro recente na Ensp, uma palestrante afirmou que é plausivel que quase $60 \%$ dos registros nos hospitais brasileiros sejam fraudulentos, devido à necessidade dos hospitais de garantir o repasse de verbas, em função dos tipos de agravos atendidos (Silos, 1990).

$\mathrm{O}$ atendimento da "demanda passiva" pelas unidades faz com que a "saúde escolar", quando implementada, trate apenas da saúde das crianças no interior das escolas. Como contemplar a saúde das crianças, em idade escolar, que não estão freqüentando a escola? A criança que vende bala na rua e tem problema de visão precisa de óculos? (Valla \& Hollanda, 1989).

Se juntarmos essas constatações com as da poluição das fábricas, com as de que o trânsito mutila e mata mais do que os assaltos e homicídios, é possivel concluir que o registro, notificação e tratamento desses agravos está muito aquém do desejado. Recentemente, o Prefeito Marcello Alencar declarou que o carioca deveria se conformar com as enchentes da mesma forma que os moradores de Tóquio se conformam com a possibilidade de terremotos. Podem ser acrescentadas a estas preocupações as encostas sem vegetação e a possibilidade de incêndios nas favelas, fazendo com que todos esses problemas sejam incluídos numa categoria de "agravos à saúde" (Carvalho, 1990; Gomes, 1990).

Este contato sistemático entre pesquisadores, profissionais e usuários, nos encontros de oficinas, foi revelando para o coletivo que, na relidade, os serviços, mesmo com toda a sua insuficiência, são apenas a ponta do iceberg e que grandes parcelas da população enfrentam um "estado de emergência" permanente.

A partir dessa reflexão, é possivel fazer um confronto entre duas concepçōes: se a falta de eficiência e eficácia dos serviços do Estado é uma carência suscetível à correção, ou se o Estado, como se apresenta hoje, é estruturalmente incapaz de resolver os agravos que hoje ameaçam a saúde da população.

O confronto dessas posturas reforça a percepção que a equipe tem da necessidade de uma intervenção mais incisiva da sociedade civil nos terrenos onde o Estado é mais ausente. Um dos instrumentos propostos para essa intervenção é o diagnóstico participativo.

Pensa-se que essa proposta, além do seu objetivo mais óbvio de fazer com que a sociedade civil tenha uma avaliação alternativa dos agravos à sua saúde, possivelmente produziria instrumentos para capacitação e o conseqüente fortalecimento das entidades populares preocupadas com a educação e saúde da classe trabalhadora. Assim, o diagnóstico participativo representa um avanço na construção da aliança entre alguns pesquisadores, profissionais e usuários preocupados com o uso do dinheiro público e com a existência de serviços de qualidade, como insumos necessários à reprodução da força de trabalho de uma forma digna.

Outra vantagem do diagnóstico participativo seria a de agrupar os "agravos à saúde" num só diagnóstico, ao contrário do Estado, que é obrigado a compartimentar aqueles fatores que afetam a saúde da população (acidentes de trânsito no Departamento de Trânsito, incêndios com o Corpo de Bombeiros, encostas e enchentes com o Departamento de Obras ou Defesa Civil, problemas de apredizagem com o Centro Municipal de Saúde, etc.).

O diagnóstico participativo seria a própria capacitação técnica, pois permitiria que técnicos e usuários se juntassem nas tarefas de discutir categorias, levantar, sistematizar e socializar dados através de um "aprender fazendo". A proposta parece crescer em importância quando se constata que hoje não há espaços reservados para este tipo de atividades. Parece importante observar, no entanto, que a proposta do diagnóstico participativo traz à tona uma polêmica velha na América Latina sobre a modalidade de investigação, que inclui 
termos tais como "pesquisa participante", "observação participante" e "pesquisa-ação". $O$ que pode estar distinguindo o diagnóstico participativo de outras propostas é a necessidade intrínsica dos atores do diagnóstico participarem efetivamente na construção e interiorização de conhecimentos sobre os agravos à saúde.

Se nos atermos a um aspecto do diagnóstico participativo - o da reconstrução histórica da área delimitada - é possível perceber com mais clareza a diferença entre investigação participativa e o método mais tradicional. Podemos imaginar um historiador, progressista, acostumado a transitar entre a população trabalhadora, preparado para as nuanças, de entrevistas e disposto a passar uma semana realizando o levantamento histórico. Mesmo devolvendo um relatório com linguagem acessivel, há diferenças substanciais entre esse método e o da população participar mais ativamente na reconstrução histórica. O exemplo é simbólico daquilo que está em discussão: se é suficiente o simples repasse de informações sobre os agravos ou se, intrinsecamente, é essencial um método que proponha a construção do conhecimento através de uma forma participante (Corragio, 1989; Gomes, 1990).

\section{ALGUMAS PALAVRAS FINAIS}

Há uma questão de fundo que permeia toda a discussão acima apresentada. Não estaria sendo a proposta uma forma sutil de mutirão, na medida em que técnicos e usuários voluntariamente executariam uma tarefa que é do Estado?

A pergunta nos remete novamente à discussão da "capacidade" ou não do Estado de executar suas responsabilidades. Se concluir da sua incapacidade, que medidas tomar?

A extrema precariedade dos serviços de saúde, juntamente com uma ameaça crescente à saúde da população, provocada por epidemias e acidentes do meio ambiente, são dados que hoje colocam em questão a validade de um conceito como "participação popular". O sentido do ato de reivindicar e pressionar, concepções intrínsicas ao uso que se faz do termo "participação popular" neste texto, pressupõe um Estado estruturalmente capaz de solucionar as ameaças à saúde da população.

Diante da gravidade das reais condições de vida e trabalho da população, possivelmente torna-se necessário modificar a abordagem do que seria participação popular. Neste sentido, um termo como "defesa civil popular" seria um conceito mais adequado, pois indicaria uma iniciativa, uma ação própria da população civil, um movimento na direção da "defesa da própria vida".

Assim, uma questão como a de que destino dar aos dados de um diagnóstico participativo criaria o confronto entre "suprir as carências dos serviços de saúde" ou "fortalecer a população organizada com um instrumento de luta".

$\mathrm{Se}$ os serviços pelos quais o Estado se responsabiliza são tão precários, porque a defesa civil seria uma exceção? É possivel constatar, aliás, que, em momentos de desastre, frequientemente é a população que toma as primeiras medidas (incêndios, enchentes, desatres de trem e automóvel), com a defesa civil demorando muito para entrar em ação.

\section{RESUMO}

VALLA, V. V. Educação, Saúde e Cidadania: Investigação Científica e Assessoria Popular. Cad. Saúde Públ., Rio de Janeiro, 8 (1): 30-40, jan/abr, 1992.

$\mathrm{O}$ autor relaciona a educação e saúde com a cidadania através da discussão dos serviços básicos e os impostos pagos pela população. As contradições decorrentes da distribuição desigual das verbas públicas, privilegiando a infra-estrutura industrial sobre o consumo coletivo, apontam à necessidade dos setores populares organizados da sociedade civil pressionarem os governos para uma política alternativa. $O$ autor propõe que profissionais das universidades públicas, como forma de serviço público, ofereçam aos setores populares da sociedade civil subsídios técnicos para suas reivindicaçōes, através dos resultados das suas investigações. Alguns resultados relativos ao centro municipal de saúde e sua relação com os usuários, tanto quanto a questão do meio ambiente com os 
agravos à saúde dos moradores das favelas do Rio de Janeiro, são exemplificados. O texto inclui uma discussão sobre a capacitação mútua dos setores populares organizados $\mathrm{e}$ profissionais da rede de serviços e/ou da universidade pública. Para isso, apresenta-se a experiência do Nesc/DCS/Ensp/Fiocruz das Oficinas de Educação e Saúde, onde lideranças populares e profissionais debatem as contradições inerentes ao serviço público com relação à eficiência e à eficácia. É proposto o diagnóstico participativo como forma dos profissionais/entidades populares lidarem com a precariedade de informações disponiveis sobre os agravos à saúde da população.

Palavras-Chave: Educação e Saúde; Cidadania; Participação Popular; Verba Pública; Assessoria Popular

\section{REFERÊNCIAS BIBLIOGRÁFICAS}

BERLINGUER, G., 1987. Medicina e política. 3" ed. São Paulo: Hucitec.

BROWN, E. R. \& MARGO, G. E., 1978. Health education: can the reformers be reformed? International Journal of Health Services, 1: 3-25.

CARVALHO, M. A. P., 1990. Vigilância epidemiológica: a busca do controle das formas de viver, adoecer e morrer. $O$ controle do destino. Vol. 2, № 3. Rio de Janeiro: Nesc/DCS/Ensp/ Fiocruz.

CORRAGIO, J. L., 1989. Pesquisa urbana e projeto popular. Espaço e Debate, 26: 22-39.

GOMES, M. L., 1990. Vigilância epidemiológica, serviços públicos de saúde e a sociedade civil. Vol. 2, № 7. Rio de Janeiro: Nesc/DCS/Ensp/ Fiocruz.

JORNAL DO BRASIL, 1988. Rio de Janeiro, 25 fevereiro, Cadernos da Cidade.

JORNAL DO BRASIL, 1988. Rio de Janeiro, 17 julho.

LICHAT, M. F., s.d.. Natural and man-made ac-cidents. In: Oxford Textbook of Public Health, vol. 1, London.

POSSAS, A. C., 1987. Descentralização e democratização do sistema de saúde. In: Anais da Conferência Nacional de Saúde, 8, pp. 241, Brasilia: Ministério da Saúde.
RIOS, R. M., 1990. Lendo o mundo no plural. Tempo e Presença, 250: 23-24.

SILOS (Sistemas Locais de Saúde), 1990. Mesa Redonda patrocinada pelo Programa de Apoio à Reforma Sanitária. Rio de Janeiro: Ensp/Pares/ Fiocruz. (Mimeo.)

SIQUEIRA, S. A. V. \& BRANDAO, E. R., 1990. Oficina de estudos sobre educação e saúde: uma proposta de trabalho. Vol. 2, № 8. Rio de Janeiro: Nesc/DCS/Ensp/Fiocruz.

STOTZ, E. N., 1989. Enfoques sobre educação $e$ saúde: notas para reflexão. Vol. 1, № 1 . Rio de Janeiro: Nesc/DCS/Ensp/Fiocruz.

STOTZ, E. N. \& NETO, O. C., 1989. Processo de trabalho e saúde. $O$ caso dos trabalhadores em Curtume. In: Demandas populares, politicas públicas e saúde (N. R. Costa, org.), vol. 2, pp. 17-74, Petrópolis: Vozes/Abrasco.

VALLA, V. V., 1988. Educação popular: libertação das classes populares ou socialização da verba pública? Educação e Sociedade, 29: 73-86.

1989. Participação popular e saúde: a questão da capacitação técnica no Brasil. Vol. 1, № 2. Rio de Janeiro: Nesc/DCS/Ensp/Fiocruz.

VALLA, V. V. \& CARDOSO DE MELO, J. A., 1987. Sem educação ou sem dinheiro. In: Saúde em estado de choque (M. C. de S. Minayo, org.), pp. 21-35. Rio de Janeiro: Espaço e Tempo.

VALLA, V. V.; STOTZ, E. N.; CARVALHO, M. A. P.; HOLANDA, E. \& SIQUEIRA, S. V. de, 1988. Educação, saúde e cidadania. Relatório final apresentado à Finep. Rio de Janeiro: Nesc/ DCS/Ensp/Fiocruz.

VALLA, V. V. \& HOLLANDA, E., 1989. Fracasso escolar, saude e cidadania. In: Demandas populares, políticas públicas e saúde (N. R. Costa, org.), pp. 103-144. Petrópolis: Vozes/Abrasco.

VALLA, V. V. \& SIQUEIRA, S. A. V., 1989. Centro municipal de saúde e participação popular. In: Demandas populares, políticas públicas e sauide (N. R. Costa, org.), vol. 1, pp. 91-116. Petrópolis: Vozes/Abrasco.

VALLA, V. V. \& STOTZ, E. N., 1989. Participação popular e saúde. $2^{2}$ ed. Petrópolis: CDDH/Cepel. 